\title{
Phagocytosis by macrophages mediated by receptors for denatured proteins - dependence on tyrosine protein kinases
}

M.R. Hespanhol and B. Mantovani

\author{
Departamento de Bioquímica e Imunologia, \\ Faculdade de Medicina de Ribeirão Preto, \\ Universidade de São Paulo, Ribeirão Preto, SP, Brasil
}

\begin{abstract}
\section{Correspondence}

B. Mantovani

Departamento de Bioquímica e

Imunologia, FMRP, USP

Av. Bandeirantes, 3900

14049-900 Ribeirão Preto, SP

Brasil

Fax: + 55-16-633-6840

E-mail: bmantova@fmrp.usp.br

Research supported by FAPESP, CAPES and FAEPA.

Received O ctober 30, 2001

Accepted January 15, 2002

Previous studies have demonstrated that some components of the leukocyte cell membrane, CR3 (Mac-1, CD11b/CD18) and p150/95, are able to bind to denatured proteins. Thus, it is of interest to know which effector functions of these cells can be triggered by these receptors when they interact with particles or surfaces covered with denatured proteins. In the present study we analyzed their possible role as mediators of phagocytosis of red cells covered with denatured bovine serum albumin (BSA) by mouse peritoneal macrophages. We observed that a) macrophages are able to recognize (bind to) these red cells, b) this interaction can be inhibited by denatured BSA in the fluid phase, c) there is no phagocytosis of these particles by normal macrophages, d) phagocytosis mediated by denatured BSA can be, however, effectively triggered in inflammatory macrophages induced by glycogen or in macrophages activated in vivo with LPS, and e) this phagocytic capacity is strongly dependent on the activity of tyrosine protein kinases in its signal transduction pathway, as demonstrated by using three kinds of enzyme inhibitors (genistein, quercetin and herbimycin A).
\end{abstract}

Key words

- Phagocytosis

- Denatured proteins

- Macrophage

- $ß_{2}$ Integrins

- Tyrosine protein kinases

\section{Introduction}

Phagocytosis is usually defined as the uptake by cells of particles visible under the light microscope $(<\sim 0.5 \mu \mathrm{m})$ and their internalization into vacuoles - a process that requires structural modifications of the cytoskeleton, including actin polymerization (13 ). In mammals the chief phagocytes are polymorphonuclear leukocytes, monocytes and macrophages. The first phase of the process is the recognition of the particle by the cell, which is a physicochemical interac- tion between components of the cell membrane and the particle, leading to attachment of the particle, and is followed by the internalization phase. Several receptors have been identified in macrophages that mediate binding and ingestion of particles. The interaction between the cells and their targets may occur directly with components of the particle surface (non-opsonic phagocytosis) or may be mediated by opsonins (antibodies, complement components, etc.) supplied by the host (opsonin-dependent phagocytosis) in which immunological receptors are in- 
volved, such as Fc $\gamma$ for $\operatorname{IgG}$, and CR3 and CR1 for complement components (4).

Integrins are another group of proteins present in cell membranes that have been shown to mediate some physiological functions of phagocytes (macrophages and polymorphonuclear leukocytes) and could also play a role in pathological conditions (5-8).

It has been observed that activated monocytes and neutrophils are able to adhere to substrates (surfaces) coated with denatured proteins through interactions mediated by Mac-1 and p150/95 $\beta_{2}$ integrins (9). This interaction may be the first step for some effector functions of these cells.

In the present study we investigated the capacity of mouse peritoneal macrophages (normal or activated) to interact (recognize) and phagocytize sheep red cells covered with denatured bovine serum albumin (BSA). Red cells are used as a convenient particle for this kind of experiment and represent a model for other particles that could bind to macrophages through this type of interaction. We also analyzed the possible participation of tyrosine protein kinases in the signal transduction pathway of the phagocytic process under these conditions by using specific enzyme inhibitors.

\section{Material and Methods}

\section{Reagents and media}

Dithiothreitol, iodoacetamide, BSA, genistein, quercetin and herbimycin A were obtained from Sigma (St. Louis, MO, USA), dimethylsulfoxide (DMSO) was from Merck (Darmstadt, Germany), and Escherichia coli lipopolysaccharide W (LPS) was from Difco Laboratories (Detroit, MI, USA). All other reagents were of analytical grade. Phosphatebuffered saline (PBS) containing $0.9 \% \mathrm{NaCl}$ and $0.007 \mathrm{M}$ sodium phosphate, $\mathrm{pH} 7.2$, was used. Hanks' medium was prepared as described in Ref. 10.

\section{Animals and cells}

BALB-c mice, 30-35 g body weight, were used as a source of peritoneal macrophages; the cells were harvested with $3 \mathrm{ml}$ Hanks' medium. Macrophages from the inflammatory exudate induced by glycogen were obtained as follows: mice received a daily ip injection of a $0.1 \%$ glycogen solution $(1 \mathrm{ml})$ and $4 \mathrm{~h}$ after the $3 \mathrm{rd}$ injection leukocytes were harvested from the peritoneal cavity. Macrophages activated by LPS were obtained 4 days after one ip injection of $50 \mu \mathrm{g}$ LPS in $0.2 \mathrm{ml}$ PBS. Normal macrophages were the cells obtained from mice that received no treatment. Sheep red cells were obtained from a local animal center in Alsever's medium.

\section{Denaturation of bovine serum albumin}

BSA was denatured as described in Ref. 9. The protein solution at $10 \mathrm{mg} / \mathrm{ml}$ in $8 \mathrm{M}$ urea, $50 \mathrm{mM}$ Tris-HCl, $\mathrm{pH}$ 8.0, was reduced with dithiothreitol for $2 \mathrm{~h}$ at $25^{\circ} \mathrm{C}$, and then alkylated with $60 \mathrm{mM}$ iodoacetamide for $2 \mathrm{~h}$ at $25^{\circ} \mathrm{C}$ in the dark. The mixture was dialyzed extensively against saline and frozen at $-20^{\circ} \mathrm{C}$.

\section{Procedure for covering sheep red cells with native and denatured BSA}

In preliminary experiments several methods for binding BSA to red cells were tested in order to find a procedure that would not alter the red cell surface and thus promote the binding of erythrocytes to macrophages independently of the presence of native or denatured BSA on its surface. We found that the method described by Poston (11), with some small modifications, was suitable for our experiments. A stock solution of $2.25 \mathrm{M}$ $\mathrm{CrCl}_{3} \cdot 6 \mathrm{H}_{2} \mathrm{O}$ in water was diluted 400 times with saline and left at room temperature for $40 \mathrm{~min}$ (this delay is necessary before addition to red cells, or agglutination might oc- 
cur). Solutions and red cells were added to a test tube in the following order: $0.6 \mathrm{ml}$ of 20 $\mathrm{mM}$ PIPES buffer, $\mathrm{pH} 6.5,0.1 \mathrm{ml}$ of the protein solution at $10 \mathrm{mg} / \mathrm{ml}, 0.1 \mathrm{ml}$ of packed red cells, and $0.1 \mathrm{ml}$ of the $\mathrm{CrCl}_{3}$ solution. The mixture was then carefully shaken and left at room temperature for $5 \mathrm{~min}$. The reaction was then interrupted by washing the red cell suspension three times with saline by centrifugation at $700 \mathrm{~g}$ for $7 \mathrm{~min}$ and the red cells were finally resuspended at $0.4 \%$ $(\mathrm{v} / \mathrm{v})$ in Hanks' medium for the phagocytosis assays. We determined that native and denatured BSA were attached to red cells by hemagglutination tests with rabbit antibodies prepared against native and denatured BSA.

\section{Phagocytosis experiments}

The phagocytosis assays with macrophages were performed as described in Ref. 12. Briefly, mouse macrophages recently harvested from the peritoneal cavity with 3 $\mathrm{ml}$ of Hanks' medium were layered onto glass coverslips and allowed to attach for 10 min at room temperature; then, after washing with Hanks' solution, the cell monolayers were incubated in plastic chambers in the same medium containing the red cell suspensions of E-BSA (red cells covered with native BSA) or E-BSAd (red cells covered with denatured BSA) at a concentration of 8 $\mathrm{x} 10^{4} \mathrm{red}$ cells $/ \mu \mathrm{l}$. After incubation at $37^{\circ} \mathrm{C}$ in an air saturated with water vapor for $30 \mathrm{~min}$, the attached and ingested red cells were differentiated by hypotonic shock treatment (five times diluted PBS, $45 \mathrm{~s}$ ) which lysed only the attached red cells. After cell fixation with glutaraldehyde and staining with Giemsa, the results were quantified by microscopic observation; at least 200 macrophages were counted in each determination. In the experiments with macrophages stimulated with glycogen or activated with LPS, the glass-adherent cells contain some polymorphonuclear leukocytes and lymphocytes be- sides macrophages; the cells were identified for quantification on the basis of conventional morphologic criteria (13).

\section{Results}

In order to assess the capacity of macrophages to bind to red cells covered with denatured BSA, which we have indicated as percent interaction (Figure 1), we measured a) the percentage of macrophages with three or more red cells (total of rosettes), b) six or more red cells (percent rosettes with great interaction), and c) the red cell/macrophage ratio, including all the macrophages in the microscopic fields. In these experiments we made no distinction between the red cells which were simply attached and those ingested (all of them had obviously interacted with the phagocyte). We observed that normal macrophages residing in the peritoneal cavity without any stimulation can bind very effectively to red cells covered with denatured BSA (a negligible interaction was observed with native BSA). The same result was observed with macrophages stimulated in vivo with glycogen or activated with LPS (in the latter, there was also a small interaction with the native protein).

Experiments of competition for macrophage binding between denatured BSA in the fluid phase and E-BSAd were performed to verify whether red cell attachment to phagocytes was mediated by the protein covering the erythrocyte (Table 1). Nearly full inhibition of interaction was observed with denatured BSA in the fluid phase and the native protein also caused some inhibition (around 50\%).

The experiments illustrated in Figure 2 show that only the macrophages stimulated in vivo with glycogen or activated with LPS were able to phagocytize red cells by interaction with denatured BSA (a small degree of phagocytosis by macrophages activated with LPS was also observed with red cells covered with native BSA). Figure 3 is an illus- 
tration of the phagocytic capacity of macrophages from the inflammatory exudate produced by glycogen.

In the experiments presented in Table 2 we analyzed the possible dependence of the phagocytic capacity of activated macrophages on the activity of tyrosine protein kinases - a group of enzymes participating in many cellular processes of signal transduction - using three inhibitors of these enzymes, genistein, quercetin and herbimycin $\mathrm{A}$, at the concentrations usually employed for this purpose in some cells, including macrophages (14-16). It is evident that the triggering of phagocytosis of E-BSAd is dependent on tyrosine protein kinase activity since marked or practically full inhibition of phagocytosis was obtained with the three enzyme inhibitors.

Figure 1. Interaction between red cells covered with native ( $E$ BSA) and denatured bovine serum albumin (E-BSAd) and normal macrophages, from the inflammatory exudate induced by glycogen, and activated by LPS. Suspensions of E-BSA or E-BSAd were incubated with macrophage monolayers for $30 \mathrm{~min}$ at $37^{\circ} \mathrm{C}$, and the interaction was quantified as follows: percentage of macrophages with three or more red cells (open bars), macrophages with six or more red cells (hatched bars), and red cell/macrophage ratio including all macrophages (gray bars). Results are reported as means \pm $\mathrm{SD}(\mathrm{N}=4$, cells from different animals). In the three groups (normal, glycogen and LPS) the differences in red cell/macrophage ratio between E-BSAd and E-BSA were significant $(* \mathrm{P}<0.05$, t-test).
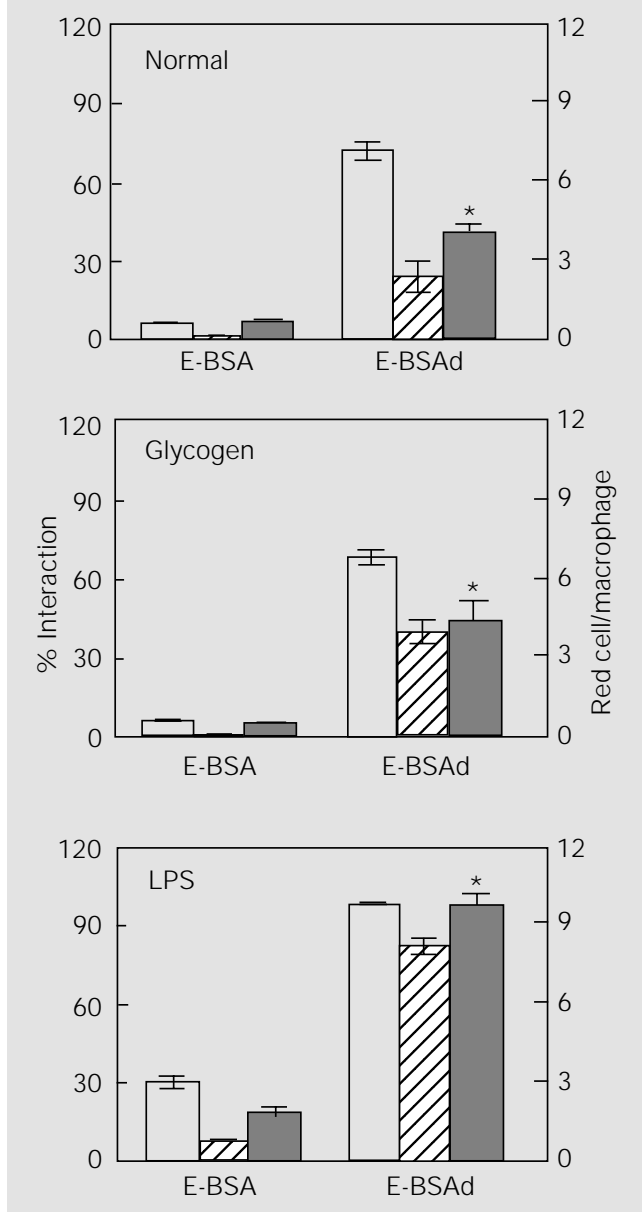

\section{Discussion}

We have shown that mouse peritoneal macrophages can recognize (bind to) red cells covered with denatured BSA. With normal macrophages the particles are able only to attach to the phagocyte membrane, but the engulfment phase is not triggered by these means; however, macrophages from the inflammatory exudate induced in vivo by glycogen or activated by LPS can effectively phagocytize these particles. There is evidence that the recognition of denatured proteins by human monocytes and neutrophils is mediated by $\beta_{2}$ integrins of the cell membrane, which have been identified as CR3 (Mac-1, CD11b/CD18) and p150/95 (9). These receptors belong to a family of leukocyte adhesion molecules that are heterodimeric proteins sharing a common $\beta$ subunit, but distinct $\alpha$ subunits (17). The cellular distribution of murine CR3 was found to be similar to the human one (18). It is thus reasonable to assume that $\mathrm{CR} 3$ and/or p150/95 are involved in the recognition of red cells covered with denatured BSA. Our experiments showing that denatured BSA in the fluid phase is able to almost fully inhibit the binding of E-BSAd to macrophages provide evidence that denatured BSA is mediating the interaction between the phagocyte and the particle. Some degree of inhibition was also obtained with the native BSA in the fluid phase. Similarity of structure may possibly account for this effect, which also agrees with the observation that native BSA can promote some adherence of monocytes to surfaces, although to a lesser extent than the denatured protein (9).

The interaction of $\mathrm{iC} 3 \mathrm{~b}$ and denatured BSA with CR3 receptors is similar in one respect: $\mathrm{iC} 3 \mathrm{~b}$ is a fragment of $\mathrm{C} 3$ and could, thus, expose amino acid sequences normally not exposed in $\mathrm{C} 3$; this is analogous to what one could expect with denatured BSA. It is known that members of the integrin family recognize the tripeptide amino acid sequence 
Arg-Gly-Asp (RGD), and iC3b contains such a sequence; however, CR3 must recognize another sequence within the iC $3 \mathrm{~b}$ molecule since a mutated form of $\mathrm{iC} 3 \mathrm{~b}$ that lacked the RGD triplet was also able to bind to recombinant CR3 (19). BSA does not contain the RGD sequence (20) and therefore the CR3 or p150/95 receptors must recognize another site in the denatured molecule. Although the capacity of these two types of receptors to bind to reduced and alkylated BSA has been established by experiments of affinity chromatography (9), the mechanism of the interaction remains to be investigated. One may also suppose that a hydrophobic region of the denatured protein could be responsible for the binding independently of any specific amino acid sequence. Also, we cannot exclude the possibility that the alkyl groups (acetamide) introduced at the sulfhydryl groups of the reduced protein may participate in the interaction.

The inhibition of phagocytosis of E-BSAd by tyrosine protein kinase inhibitors (genistein, quercetin and herbimycin A) indicates that these enzymes are involved in the signal transduction pathway of the engulfment phase triggered by CR3 or p150/95, or both, in inflammatory and activated macrophages; this same dependence was observed in phagocytosis mediated by Fc $\gamma$ receptors using genistein as the enzyme inhibitor (16). We have also confirmed this finding in phagocytosis experiments of red cells covered with IgG antibodies employing the same three enzyme inhibitors used in our experiments with E-BSAd. We observed practically full inhibition of phagocytosis (expressed as red cell/macrophage ratio) with genistein and quercetin (96 \pm 2 and $100 \pm 0 \%$, respectively, $\mathrm{N}=3$ ) and a marked inhibition with herbimycin A $(61 \pm 4 \%, N=4)$. We should keep in mind, however, that these drugs can possibly have other effects on cells besides inhibition of tyrosine protein kinases; for example, quercetin was shown to inhibit also serine/threonine protein kinases (15).
There are indications that genistein could be the most specific one (21) and therefore it is advisable to use more than one such inhibitor, as done here. There is, thus, the same dependence on the activity of tyrosine protein kinases in phagocytosis mediated by

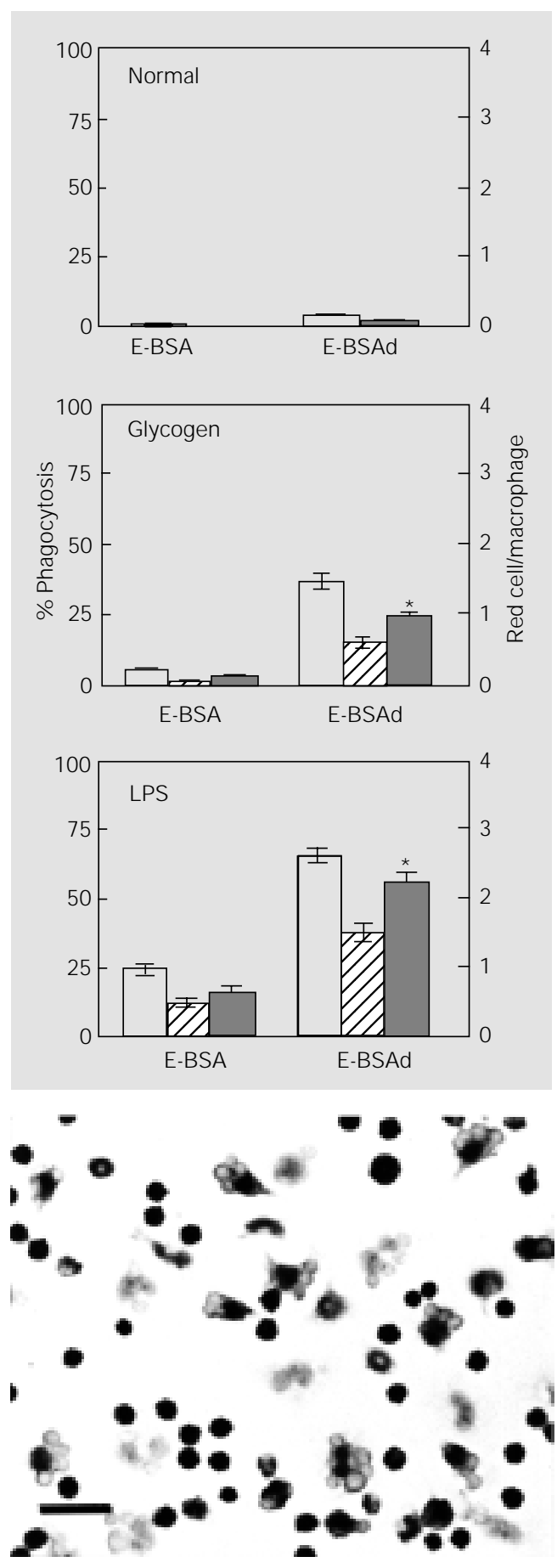

Figure 2. Phagocytosis of red cells covered with native (EBSA) and denatured bovine serum albumin (E-BSAd) by normal macrophages, from the inflammatory exudate induced by glycogen, and activated by LPS. Experimental conditions are the same as described in the legend to Figure 1 , with the exception that after 30 min of incubation the cell monolayers were subjected to a hypotonic shock treatment to lyse all the attached red cells, leaving only the ingested ones. Percent phagocytosis is indicated by the percentage of macrophages that ingested at least one red cell (open bars) and the percentage of macrophages that ingested three or more red cells (hatched bars); the red cell/macrophage ratio is the ratio between the number of ingested red cells and the total number of macrophages counted (gray bars). Results are reported as means \pm $\mathrm{SD}(\mathrm{N}=4$, cells from different animals). In the glycogen as well as in the LPS groups the differences in red cell/macrophage ratio between E-BSAd and E-BSA were significant $(* \mathrm{P}<0.05$, t-test).

Figure 3. Phagocytosis of EBSAd (red cells covered with denatured BSA) by macrophages from the inflammatory exudate induced by glycogen. The experimental conditions are the same as in Figure 2. Bar = $33 \mu \mathrm{m}$. 
these two types of receptors.

If different receptors can trigger phagocytosis it is reasonable to suppose that there should be convergent biochemical pathways leading to the final reaction of polymerization of G-actin to F-actin which is an essential component for engulfment $(2,3)$. The activation of tyrosine protein kinases could represent one of the points of convergence, although possibly different sets of enzymes and protein phosphorylations might be in-

Table 1. Effect of fluid-phase denatured bovine serum albumin (BSAd) and native BSA on the interaction between macrophages and red cells covered with denatured BSA (E-BSAd).

Preincubation \% Rosettes Red cell/macrophage

\begin{tabular}{lrl}
\hline Hanks & $62 \pm 6.0$ & $3.70 \pm 0.40$ \\
BSAd & $2 \pm 0.7$ & $0.34 \pm 0.08$ \\
BSA & $34 \pm 0.4$ & $2.10 \pm 0.06$
\end{tabular}

Normal macrophages attached to glass coverslips were preincubated for $15 \mathrm{~min}$ at $37^{\circ} \mathrm{C}$ with Hanks' medium, BSAd or BSA, dissolved in Hanks' medium at a concentration of $10 \mathrm{mg} / \mathrm{ml}$. Red cells and macrophages were then incubated for $30 \mathrm{~min}$ at $37^{\circ} \mathrm{C}$ and the interaction was quantified by determining percent rosettes (percent macrophages with three or more red cells) and red cell/macrophage ratio (the ratio between the number of red cells taken up and the number of macrophages counted). Results are reported as means \pm SD ( $\mathrm{N}=4$, cells from different animals).

Table 2. Inhibition of E-BSAd phagocytosis by LPS-activated macrophages caused by treatment with tyrosine protein kinase inhibitors.

Inhibitor

Inhibitor

Genistein $150 \mu \mathrm{M}$

Quercetin $300 \mu \mathrm{M}$

Herbimycin A $1.7 \mu \mathrm{M}$

Macrophages activated in vivo with LPS were preincubated at $37^{\circ} \mathrm{C}$ for $10 \mathrm{~min}$ with tyrosine kinase inhibitors. Phagocytosis assays were performed in the presence of the inhibitors. Results are reported as percent inhibition relative to the control for each cell preparation (paired experiments), and calculated as follows: percent inhibition $=100 \mathrm{x}$ (control - test)/control. Data are reported as means \pm SD of 3 to 4 experiments (different animals). volved when different receptors trigger the process.

The fact that some kind of particles can bind to phagocytes but the interaction does not trigger the mechanism of internalization has been long known. Thus, red cells interacting through $\mathrm{iC} 3 \mathrm{~b}$ bind very effectively to mouse macrophages and polymorphonuclear leukocytes but remain on the cell surface; when $\operatorname{IgG}$ (Fc $\gamma$ receptors) are involved in the interaction the engulfment phase is triggered $(22,23)$. However, when macrophages are activated, the interaction mediated by $\mathrm{iC} 3 \mathrm{~b}$ (CR3 receptors) leads to phagocytosis (12, $24)$. This situation is analogous to that observed here for the interaction mediated by denatured BSA. The mechanism whereby CR3 receptors become able to trigger phagocytosis in inflammatory or activated macrophages is not clear. Some observations suggest a requirement of receptor clustering (25) but there are also indications that the mechanism may depend on the phosphorylation of serine residues in the $\beta$ subunit of the receptor (26).

The presence of denatured proteins at a tissue site may be a signal for macrophages to adhere and accumulate at that site. However, effector functions such as phagocytosis require additional signals for activation to enable the cells to perform this function, which physiologically means triggering their destructive powers. The possibility of this control is another example related to the different roles of normal and inflammatory or activated macrophages.

\section{Acknowledgments}

We thank Silvana Chedraoui Silva for help with some experiments; we are also grateful to her and Dr. Victor Diaz Galban for valuable help with graphic computation. We acknowledge José Antonio da Silva for technical assistance and Maria Thereza Rodrigues for expert assistance in the preparation of the manuscript. 


\section{References}

1. Rabinovitch M (1995). Professional and non-professional phagocytes: an introduction. Trends in Cell Biology, 5: 85-87.

2. Greenberg $S$ (1995). Signal transduction of phagocytosis. Trends in Cell Biology, 5 : 93-99.

3. Oliveira CA, Kashman $Y \& \&$ Mantovani $B$ (1996). Effects of latrunculin A on immunological phagocytosis and macrophage spreading-associated changes in the $\mathrm{F}$ actin/G-actin content of the cells. Chemico-Biological Interactions, 100: 141-153.

4. Aderen A \& Underhill DM (1999). Mechanisms of phagocytosis in macrophages. Annual Review of Immunology, 17: 593623.

5. Ugarova TP \& Yacubenco VP (2001). Recognition of fibrinogen by leukocyte integrins. Annals of the New York Academy of Sciences, 936: 368-385.

6. Piccardoni $P$, Sideri $R$, Manarini $S$, Piccoli A, Martelli N, de Gaetano G, Cerletti C \& Evangelista $V$ (2001). Platelet/polymorphonuclear leukocyte adhesion: a new role for SRC kinases in Mac-1 adhesive function triggered by P-selectin. Blood, 98: 108-116.

7. Reichert F, Slobodov U, Makranz C \& Rotshenker $S$ (2001). Modulation (inhibition and augmentation) of complement receptor-3-mediated myelin phagocytosis. Neurobiology of Disease, 8: 504-512.

8. Weitz-Schmidt G, Welzenbach K, Brinkman V, Kamata T, Kallen J, Bruns C, Cottens S, Takada Y \& Hommel U (2001). Statins selectively inhibit leukocyte function antigen-1 by binding to a novel regulatory integrin site. Nature Medicine, 7: 687-692.

9. Davis GE (1992). The Mac-1 and p150,95 $B_{2}$ integrins bind denatured proteins to mediate leukocyte cell-substrate adhesion. Experimental Cell Research, 200:
242-252.

10. Paul J (1970). Cell and Tissue Culture. E \& S Livingstone Ltd., Edinburgh, Scotland, 86-119.

11. Poston RN (1974). A buffered chromic chloride method for attaching antigens to red cells: use in haemagglutination. J ournal of Immunological Methods, 5: 91-96.

12. Mantovani B (1981). Phagocytosis of immune complexes mediated by IgM and C3 receptors by macrophages from mice treated with glycogen. J oumal of Immunology, 126: 127-130.

13. Thompson J \& van Furth R (1970). The effect of glucocorticosteroid on the kinetics of mononuclear phagocytes. J ournal of Experimental Medicine, 131: 429-442.

14. Rankin BM, Yocum SA, Mittler RS \& Kiener PA (1993). Stimulation of tyrosine phosphorylation and calcium mobilization by $\mathrm{FC} \gamma$ receptor cross-linking. J ournal of Immunology, 150: 605-616.

15. Hidaka H \& Kobayashi R (1992). Pharmacology of protein kinase inhibitors. Annual Review of Pharmacology and Toxicology, 32: 377-397.

16. Greenberg S, Chang P \& Silverstein SC (1993). Tyrosine phosphorylation is required for Fc receptor-mediated phagocytosis in mouse macrophages. J ournal of Experimental Medicine, 177: 529-534.

17. Hynes RO (1992). Integrins: versatility, modulation, and signaling in cell adhesion. Cell, 69: 11-25.

18. Greenberg S \& Silverstein SC (1993). Phagocytosis. In: Paul WE (Editor), Fundamental Immunology. 3rd edn. Raven Press, New York, 941-964.

19. Tanaguchi-Sidle A \& Isenman DE (1992). Mutagenesis of the arg-gly-asp triplet in human complement $\mathrm{C} 3$ does not abolish binding of iC $3 \mathrm{~b}$ to the leukocyte integrin complement receptor type III (CR3,
CD11b/CD18). Journal of Biological Chemistry, 267: 635-643.

20. NCBI, PubMed, Sequence Viewer. Available at: http://www.ncbi.nlm.nih.gov/ PubMed. Accessed October 9, 2001.

21. Akiyama T, Ishida J, Nakagawa S, Ogawara $\mathrm{H}$, Watanabe S, Itoh N, Shibuya M \& Fukami Y (1987). Genistein, a specific inhibitor of tyrosine-specific protein kinases. J ournal of Biological Chemistry, 262: 5592-5595.

22. Mantovani $B$, Rabinovitch $M \&$ Nussenzweig V (1972). Phagocytosis of immune complexes by macrophages. Different roles of macrophage receptor sites for complement (C3) and for immunoglobulin (IgG). J oumal of Experimental Medicine, 135: 780-792.

23. Mantovani B (1975). Different roles of IgG and complement receptors in phagocytosis by polymorphonuclear leukocytes. J ournal of Immunology, 115: 15-17.

24. Bianco C, Griffin J r FM \& Silverstein SC (1975). Studies of the macrophage complement receptor. Alteration of receptor function upon macrophage activation. J ournal of Experimental Medicine, 141: 1278-1290.

25. Detmers PA, Wright SD, Olsen E, Kimball B \& Cohn ZA (1987). Aggregation of complement receptors on human neutrophils in the absence of a ligand. J ournal of Cell Biology, 105: 1137-1145.

26. Buyon J P, Slade SG, Reibman J , Abramson SB, Phillips MR, Weissmann G \& Winchester R (1990). Constitutive and induced phosphorylation of the alpha- and beta-chains of CD11/CD18 leukocyte integrin family. Relationship to adhesiondependent functions. J ournal of Immunology, 144: 191-197. 